\title{
Kinetic modeling and study of H-ZSM-5 coated silicon carbide ceramic foam in toluene methylation to produce xylene
}

\author{
Debarpita Ghosal $^{1} \cdot$ Uttam Maity $^{2} \cdot$ Sonali Sengupta $^{2} \cdot$ Jayanta Kumar Basu $^{2}$
}

Received: 17 November 2015 / Accepted: 8 October 2017/Published online: 26 October 2017

(c) The Author(s) 2017. This article is an open access publication

\begin{abstract}
This work deals with the toluene alkylation reaction with methanol catalyzed by commercial H-ZSM-5 coated over $\mathrm{SiC}$ foam. The main product is xylene which is a well-known building block of many petrochemicals. The foam has been purchased and H-ZSM-5 was coated on it by dip-coating method. The coated foam was used as a catalyst block to study the reaction of toluene with methanol. The effect of variation of different reaction parameters such as reaction temperature, mole ratio of reactants, $W /$ $F$ ratio, partial pressure, feed rate, number of ceramic block coated with catalyst was investigated. Effect of regeneration of the catalyst has also been studied. In addition, comparison of conversion with pellet and coated one was also studied to confirm the usefulness of ceramic foam as catalyst support to get the best conversion to xylene production.
\end{abstract}

Keywords Ceramic foam $\cdot$ H-ZSM-5 $\cdot$ Xylene $\cdot$ Toluene $\cdot$ Methanol $\cdot$ Langmuir-Hinshelwood model

\section{Introduction}

Application of the catalysts, supported on different suitable structures, are advantageous in versatile organic reactions as they offer good mass and heat transfer effect in reactions compared to the powdered or pelleted catalysts in

Debarpita Ghosal

ghosal.debarpita@gmail.com

1 Department of Chemical Engineering, C.V. Raman College of Engineering, Bhubaneswar, Orissa 752054, India

2 Department of Chemical Engineering, Indian Institute of Technology, Kharagpur, Kharagpur 721302, India flow reactors [1]. Deposition of a thin layer of active catalyst on the wall of the structured support by wash or dipcoating is preferred over pelletized catalyst as a lesser amount of catalyst is dispersed on a relatively large surface area, which in turn, improves the interfacial reaction rate. Moreover, structured support with highly interconnected porous network exhibits low pressure drop in catalytic bed [2].

Two types of highly porous structured supports are popular, honeycomb and reticulated. The reactant vapor passes unidirectionally through the regular hexagonal channels of the honeycomb structure causing low pressure drop, whereas reticulated structure is an interconnected porous form which imparts a thorough radial mixing and good heat dissipation within the structure decreasing the heat transfer effect in the catalyst bed. Although, zeolites used in fixed beds in the form of extrudate pellets are very effective catalysts, but these have many disadvantages such as high pressure drop in the catalyst bed, high diffusional effect and pore-mouth blockage. It was also known that the foam-supported catalyst enhances the reaction rate significantly over the pellets [3].

Among the zeolites, the acidic ones such as zeolite $X$ and Y [4-7], zeolite $\beta$ [8, 9], mordenite [10] and ZSM-5 [11-17] are widely used catalysts for alkylation reaction. The deposition of an active catalyst can be conventionally done by coating the ceramic foam support by slurry of catalytic material containing a binder to ensure adhesion of the layer [18-20]. Most of the ceramic catalyst supports possess very low surface area which is below $1 \mathrm{~m}^{2} / \mathrm{g}$. The specific surface area of both honeycomb and reticulated foams can be increased up to $40 \mathrm{~m}^{2} / \mathrm{g}$ by washcoating with the catalyst [18]. It was generally observed that the selectivity of coke increases with the increase in pore size [21]. It has been supported by the previous literature [22] that, 
among the other zeolites, H-ZSM-5 shows very slow rate of coking due to its low acid site density and this property dominates over the criterion of its average pore size. Literature related to the work on H-ZSM-5 proves the application of H-ZSM-5 as alkylation catalyst which emphasizes towards the para selective products [15, 23]. It has been observed that H-ZSM-5 possesses better washcoat stability compared to mordenite and ferrite [24].

Ample literature has been obtained on the alkylation of aromatics over pelletised H-ZSM-5 as catalyst such as methylation [25-33], ethylation [25, 34, 35], isopropylation [31, 36], butylation [37], etc. Methylation of toluene is one of the simplest reactions which can be studied as a key reaction over H-ZSM-5 catalyst supported on ceramic foam to establish the performance of structured foamsupported catalyst. Few literatures have been obtained on the reaction kinetics over foam-supported catalysts. Richardson et al. investigated the kinetics of carbon dioxide reforming over metal-supported alumina loaded on ceramic foam [38]. Aleksandrov et al. had studied the kinetics of oxidation of carbon monoxide on the synthetic ceramic foam-supported catalysts [39]. No literature has been found till now on the kinetic study of methylation of toluene on H-ZSM-5 supported on ceramic foam.

Among many types of structured supports, silicon carbide ceramic foam is chosen for the present work because of its superior physical properties such as thermal conductivity, chemical inertness and mechanical strength compared to refractory oxide-based conventional foam support [40]. Other causes of choosing silicon carbide foam as a structured support are its low cost, high surface area and easy availability.

The objective of the present work deals with the study of silicon carbide foam-supported ZSM-5 catalyst towards the methylation of toluene with methanol with the perspective of rate kinetics. The foam is reticulated in nature. ZSM-5 is coated on ceramic foam by the method of washcoating/dipcoating. The present work uses foam of 30 pores per inch.

\section{Materials and methods}

\section{Materials}

Commercial H-ZSM-5, bentonite powder, acetone, aluminum nitrate nonahydrate $(95 \%)$ and soluble starch, procured from Merck India Ltd., were the chemicals used for preparation of catalyst pellet, dip-coating and pretreatment of ceramic foam. Toluene (99\%) (Merck India Ltd.) and methanol (99.5\%) (Spectrochem Pvt. Ltd.) were used for the alkylation reaction of toluene with methanol.

\section{Preparation of pellet and dip-coated ceramic foam with powder catalyst}

Cylindrical pellet of $2 \mathrm{~mm}$ diameter was prepared by a hand extruder with different catalyst powders such as alumina, H-ZSM-5, $\beta$ zeolite, modified H-ZSM-5 and modified $\beta$ zeolite. The binder used for pelleting was bentonite clay. The catalyst powder and bentonite clay were mixed together thoroughly, according to the different weight proportions of catalyst to bentonite (e.g., 50:50, $60: 40,70: 30,80: 20)$ to prepare a paste with water, which was then managed to fill the hand extruder and pressed manually to come out in the shape of a noodle. The noodles were cut into small equal extrudate forms followed by drying in an air oven at $120^{\circ} \mathrm{C}$ for $3 \mathrm{~h}$ and calcining at $550{ }^{\circ} \mathrm{C}$ for $3 \mathrm{~h}$. It was found that a weight proportion of $80 \%$ catalyst and $20 \%$ bentonite clay had well enough strength to use in the reactor during reaction without any breakage or loss in weight of the catalyst. Therefore, this proportion of H-ZSM-5 and bentonite clay was established to be used for further experiments.

\section{Washcoating of catalyst on SiC block}

Each of the ceramic block was pretreated by cleaning with distilled water followed by acetone, and then dried in an oven for $3 \mathrm{~h}$ prior to the washcoating/dip-coating procedure. Dip-coating was performed in a Single Dip-Coater (model no. SDC 2007C) supplied by Apex Instruments Ltd., Kolkata, India. This instrument works for controlled immersion and withdrawal of substrates from thereof, ideal for sol-gel coatings and monolayer assembly and layer by layer assemblies.

The dip-coating of the catalyst on the $\mathrm{SiC}$ foam was done by preparing slurry of definite quantity of catalyst powder and dipping the foam into that for a particular time period in the dip-coater. A typical slurry of catalyst consisting of $20 \mathrm{~g}$ catalyst powder, $5 \mathrm{~g}$ aluminum nitrate as binder, $7 \mathrm{~g}$ starch as viscosity modifier in water was prepared and a number of trials have been attempted to optimize this slurry composition. The $\mathrm{SiC}$ foam was dipped into this slurry, kept in stirring condition in the dip-coater for about $3 \mathrm{~h}$. The excess of suspension in the pores of the foam was removed by flushing with an air flow. It was then dried at $120{ }^{\circ} \mathrm{C}$ for $3 \mathrm{~h}$ and calcined at $550{ }^{\circ} \mathrm{C}$ for $3 \mathrm{~h}$ to avoid cracks in the coating. Several coatings were applied by consecutive dip-coatings with drying and high temperature calcinations in between each step to acquire the required catalyst amount with perfect adherence. 
Fig. 1 Schematic diagram of the experimental set-up

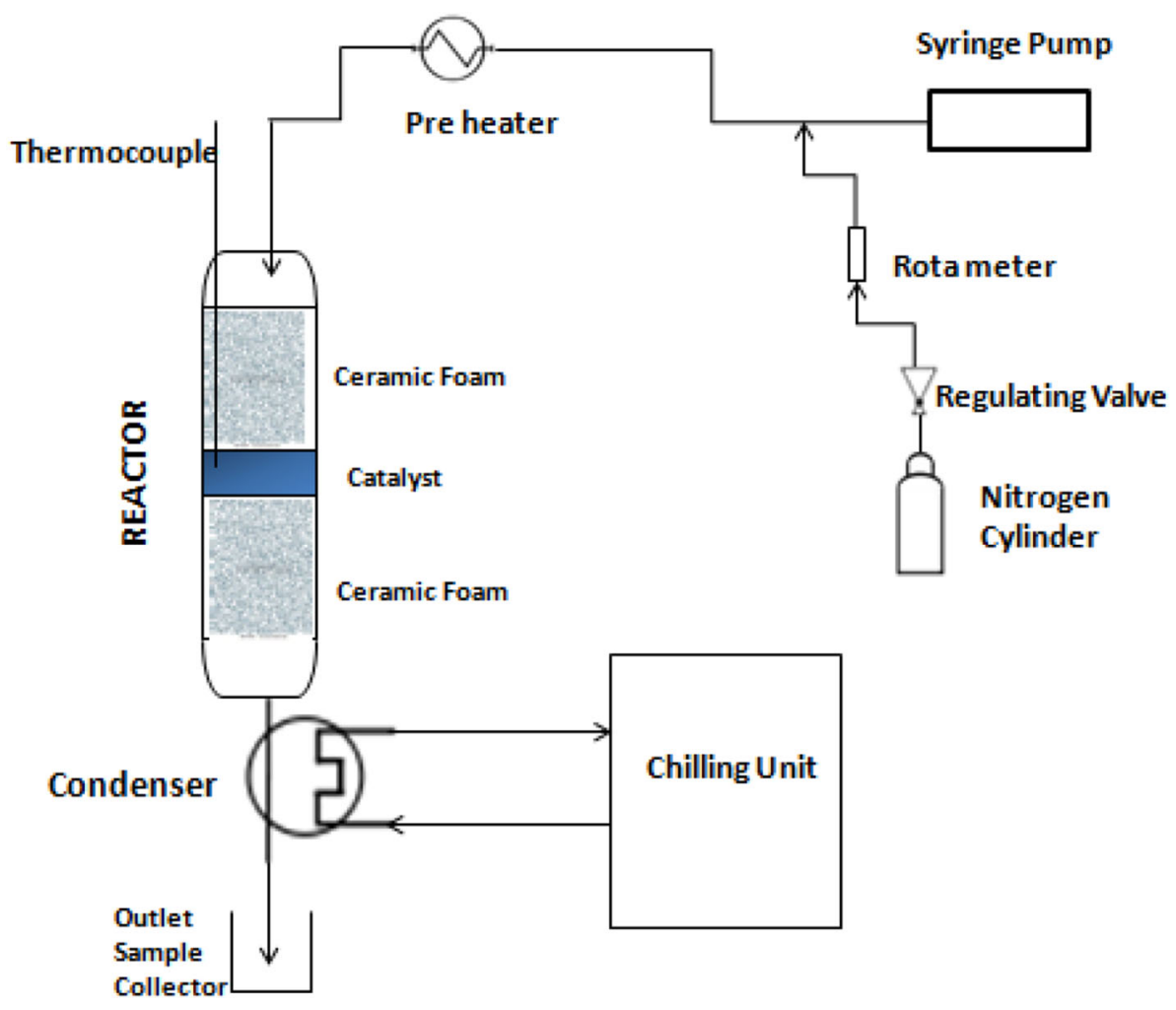

\section{Characterization of different catalysts}

\section{SEM, EDXS and X-ray mapping}

The surface morphology and microstructural analysis of untreated H-ZSM-5, $\beta$ zeolite, their metal modified forms, blank SiC foam and catalyst-coated form has been conducted both by JEOL JSM5800 scanning electron microscope (SEM) with EDS detector (Oxford ISIS-300) and Zeiss Evo 60 SEM, Germany with energy dispersive X-ray spectroscopy (EDXS, Inca Penta FET X3, Oxford Instrument, UK). In sample preparation step, the sample is finely powdered and made moisture-free by heating in an oven for $2 \mathrm{~h}$ at $120{ }^{\circ} \mathrm{C}$. For blank or catalyst-coated ceramic foam, a very small portion of the foam was taken for the micrograph. Scanning has been done on a particular chosen portion of the sample with different scales and magnification according to the requirement. Elemental analysis was done through EDXS.

$\mathrm{X}$-ray mapping provides powerful visual information on the spatial distribution of elemental constituents at micrometer lateral resolution and is one of the most widely applied qualitative analysis procedures. The distribution of different elements can be visualized in a particular scanned area of the sample.

\section{BET surface area analysis}

The porous nature of the catalyst was analyzed by employing the standard volumetric nitrogen adsorption method with the Brunauer, Emmett and Teller (BET) surface area analyzer (Autosorb-1, Model: AS1 MP/ChemiLP, Quantachrome Instruments, USA). The isotherms were obtained by monitoring the nitrogen adsorption/desorption data points at relative pressures ranging from $10^{-6}$ to 1 bar. These data were utilized to calculate the specific surface area, pore volume and average pore diameter of the different catalysts. At the initial stage, samples were degassed for $3 \mathrm{~h}$ at $300{ }^{\circ} \mathrm{C}$.

\section{Ammonia temperature programmed desorption (TPD)}

The acidity distribution profile of different catalysts was recorded by TPD technique using ChemBET-3000-TPD/ TPR instrument (Quantachrome Instruments, USA) equipped with thermal conductivity detector. For analysis, $0.213-0.222 \mathrm{~g}$ of the powder catalyst samples was used and taken in the quartz U-shaped tube. The samples were degassed by passing He gas over the sample. The degassing procedure was continued at a temperature of $200{ }^{\circ} \mathrm{C}$. The He gas was then replaced by $\mathrm{NH}_{3}$ which was passed for 
$10 \mathrm{~min}$ at the flow rate of $80 \mathrm{~mL} / \mathrm{min}$. After saturation with $\mathrm{NH}_{3}$, He gas was passed to purge the sample for $15 \mathrm{~min}$. The temperature was increased at a rate of $10{ }^{\circ} \mathrm{C} / \mathrm{min}$ and data acquisition was started.

\section{$X$-ray diffraction study}

The crystalline nature of all powder samples and their change in crystallinity after different modifications were done by X-ray diffraction (XRD) study with the help of an X-ray diffractometer PW-1710, Phillips, using $\mathrm{Cu} \mathrm{K} \alpha$ radiation $(\lambda=1.54 \AA)$ within the $2 \theta$ range of $10^{\circ}-90^{\circ}$. The samples were analyzed and the data generated were compared with standard International Centre for Diffraction Data (1996, ICDD) database for further information.

\section{Fourier-transform infrared spectroscopy}

Fourier-transform infrared spectroscopy (FTIR) is the technique which is used to determine the functional group present in the samples and also any variation in intensity of spectra in the FTIR image. FTIR spectroscopy analysis of sample was done by Perkin Elmer, spectrometer-100, USA. In the process, a pellet was made by grinding and mixing the finely powdered sample collectively with analytical grade $\mathrm{KBr}$ and analyzed within the wavelength range of $4000-400 \mathrm{~cm}^{-1}$ to get the spectra.

\section{Experimental set-up}

The experimental set-up mainly consists of a feed-inlet pump, preheater, reactor and sample collection units. The detailed description of the set-up is given in Fig. 1.

\section{Feed inlet-section}

The liquid reactant mixture is fed by a syringe pump (Miclins-SP-01, India) (Fig. 1) consisting of a $30 \mathrm{~mL}$ glass syringe and $2 \mathrm{~mm}$ i.d. flexible tubing to connect to the inlet of the preheater. The time and rpm are both adjustable according to the requirement prior to the reaction. The flow range of the syringe pump varies from 0.1 to $125 \mathrm{~mL} / \mathrm{h}$ depending on the rpm set. The carrier gas nitrogen is supplied from the nitrogen cylinder along with pressure regulator. The flow rate of the carrier gas was measured by rotameter and maintained between 2.5 and $25 \mathrm{~mL} / \mathrm{min}$, depending on the requirement of the reaction.

\section{Preheater-reactor assembly}

The syringe pump is connected to the preheater fixed horizontally. The preheater is assembled with the reactor.
The preheater is a cylindrical tube with an i.d. of $20 \mathrm{~mm}$, made up of stainless steel and properly insulated. The reaction temperature in the catalyst bed was measured with the help of a thermocouple which is coupled with a digital temperature controller.

The reactor is fabricated to house the ceramic foam blocks coated with catalyst of a particular dimension (42 mm $\times 42 \mathrm{~mm} \times 15 \mathrm{~mm}$ ). The reactor is made up of stainless steel and having a square cross-sectional area. It has the dimension $42 \mathrm{~mm} \times 42 \mathrm{~mm} \times 200 \mathrm{~mm}$. At the preliminary stage of the catalyst loading process, a wire mesh of $40 \mathrm{~mm} \times 40 \mathrm{~mm} \times 1 \mathrm{~mm}$ dimension was placed exactly beneath the reactor to support the catalyst bed. Catalyst-coated $\mathrm{SiC}$ foam is placed at the middle of the reactor. Inert ceramic beads were packed on both sides of the catalyst foam within the reactor. The reactor, along with the thermocouple properly inserted up to the middle of it, was then fixed with the whole set-up by suitably attaching it with the preheater and the product outlet tube. The maximum allowable temperature of the reactor is $450{ }^{\circ} \mathrm{C}$. The outlet of the reactor is connected with a condenser. The reaction vapor was cooled with the waterethylene glycol mixture $(60: 40 \mathrm{v} / \mathrm{v})$ circulated by chiller (Fig. 1) through the condenser. The reactor is kept in an insulated metal jacket with glass wool insulation to minimize the heat loss from the reactor during heating and reaction.

\section{Experimental procedure and product analysis}

Alkylation reactions were carried out using different catalysts coated on $\mathrm{SiC}$ foam placed in the flow reactor described in the preceding section. SiC blocks coated with catalyst are placed properly within the reactor. Nitrogen as a carrier gas is allowed to flow at a rate of $5 \mathrm{~mL} / \mathrm{min}$ during activation stage of the catalyst for $4-5 \mathrm{~h}$. The catalyst bed is preheated to attain the steady reaction temperature prior to the reaction. Various reactants, mixed at different proportions, were vaporized and heated at the desired temperature in the preheater in a flow of nitrogen as carrier gas. The reaction mixture was then passed through the catalyst bed. Chiller is set at the temperature -2 to $-10{ }^{\circ} \mathrm{C}$ with the ethylene glycol and water mixture.

In a typical experimental run, $30 \mathrm{~mL}$ of the reactant mixtures at a known molar ratio is taken in the syringe pump (Miclins-SP-01) having a syringe capacity of $30 \mathrm{~mL}$. The reactants are fed to the reactor through a preheater. The product vapor is condensed in a condenser and collected at a definite time interval.

The reaction samples were analyzed in a Chemito gas chromatograph (Model GC 8610), fitted with a flame ionization detector. The columns used for the studies are SE30 and OV-17 column with $0.8^{\prime \prime}$ i.d. and 2 m length for 
both. Nitrogen was used as the carrier gas with a flow rate of $20 \mathrm{~mL} / \mathrm{min}$. The $\mathrm{GC}$ conditions for analysis are set properly according to the reaction.

For toluene alkylation reaction with methanol, injection temperature was set at $150{ }^{\circ} \mathrm{C}$, oven temperature at $75^{\circ} \mathrm{C}$ and detector temperature at $200{ }^{\circ} \mathrm{C}$. The column temperature was programmed with an initial temperature of $75^{\circ} \mathrm{C}$ and increased with a ramp rate of $5{ }^{\circ} \mathrm{C} / \mathrm{min}$ up to $200{ }^{\circ} \mathrm{C}$.

\section{Results and discussions}

\section{XRD analysis}

From the XRD plots of coated and uncoated ceramic foams, appearance of sharp peaks at $2 \theta$ degrees of $25.3^{\circ}$, $41.38^{\circ}, 44.6^{\circ}$ and $53^{\circ}$ in both the cases were observed (Fig. 2), which may be due to the presence of the SiC hexagonal closed packed crystal structure (standard ICDD database). The foam after coating showed less intense peak at the same diffraction angle 41.8 and 44.6. The reduced intensity in the same peak implies the loss of crystallinity of the material. Three consecutive peaks at $2 \theta$ of $26.85^{\circ}$, $27.85^{\circ}$ and $28.35^{\circ}$ observed in the XRD plots of H-ZSM-5 confirm the presence of a typical H-ZSM-5 structure.

\section{Scanning electron microscopic (SEM) image and EDXS analysis}

The SEM images of powder H-ZSM-5, ceramic foamcoated H-ZSM-5 and uncoated foam are shown in Fig. 3ac, respectively. Some differences in morphology have been observed between coated and uncoated foam. The sharpness of the corner of the particles in coated foam is observed to reduce in comparison to that of the uncoated one. The SEM images of uncoated and coated strut and

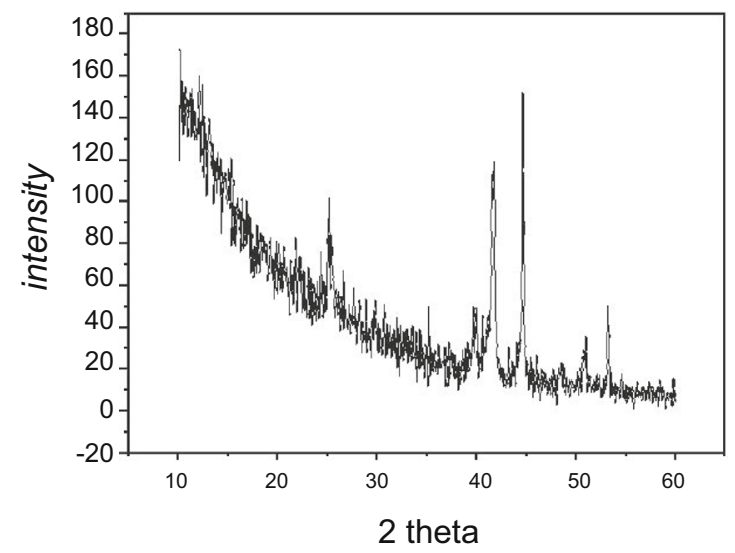

(a) window of foam are shown in Fig. $4 \mathrm{a}$ and b, respectively, and it is evident that the coated strut and window are having higher roughness compared to the uncoated strut. One of the reasons of increasing surface area of the catalyst is probably due to the increase in roughness in the strut and window.

\section{Energy dispersive X-ray spectroscopic analysis}

The Si to Al ratio of the H-ZSM-5 was found to be around 16 from the quantitative chemical analysis by EDXS (Table 1).

\section{BET analysis}

The results of the BET surface area measurement reveal that the total surface area of the washcoated ceramic foam is almost double compared to the uncoated one (Table 2) and the reason for this may be due to the deposition of high surface area H-ZSM-5 catalyst powder (surface area $260 \mathrm{~m}^{2} / \mathrm{g}$ ) on the foam surface. It is reported that the surface area of foam can be increased from 1 to $40 \mathrm{~m}^{2} / \mathrm{g}$ through washcoating with high surface area material $[18,41]$.

The nitrogen adsorption-desorption isotherms of H-ZSM-5 are displayed in Fig. 5a. The steep initial region of the hysteresis loop is due to the very strong adsorption of the gas which implies the presence of micropores. But the existence of very small hysteresis loop supports the presence of very small amount of mesopores in the sample.

It is evident from the differential pore volume distribution of H-ZSM-5 powder shown in Fig. 5b, that the pore width/diameter of the majority of the pores in the H-ZSM-5 is less than $20 \AA$ which suggests that the catalyst is a highly microporous type (according to IUPAC-1984).

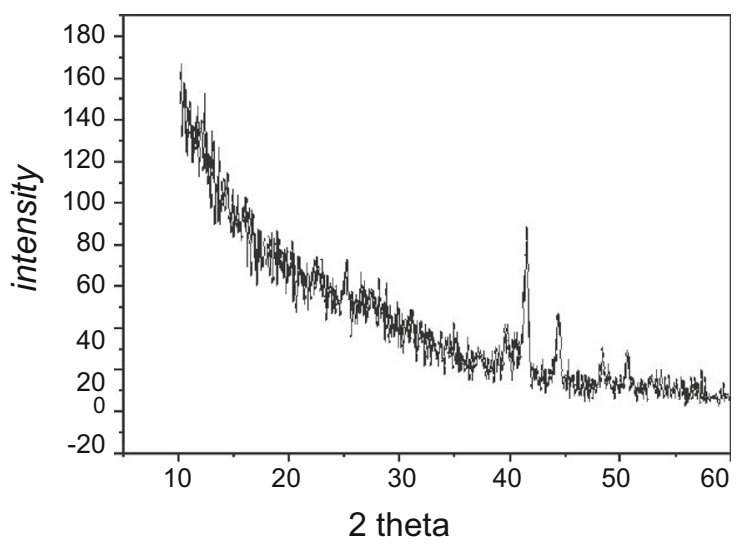

(b)

Fig. 2 XRD plot of blank $\mathrm{SiC}$ foam (a), H-ZSM-5 coated SiC foam (b) 
Fig. 3 a SEM image of

H-ZSM-5 powder, b H-ZSM-5 coated and $\mathbf{c}$ uncoated ceramic foam surface

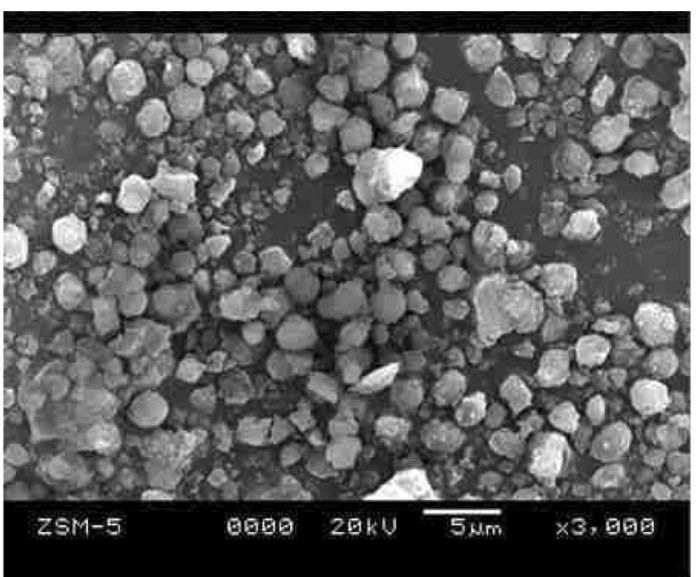

(a)

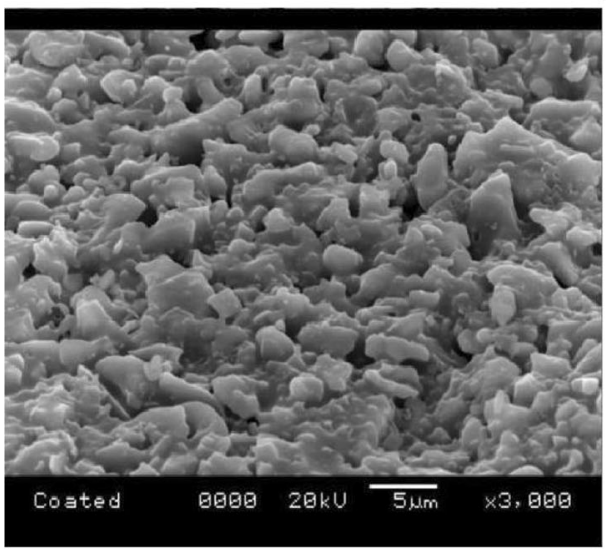

(b)

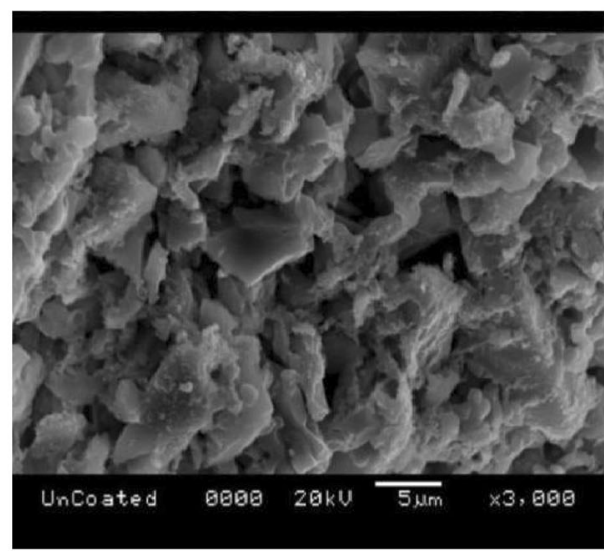

(c)

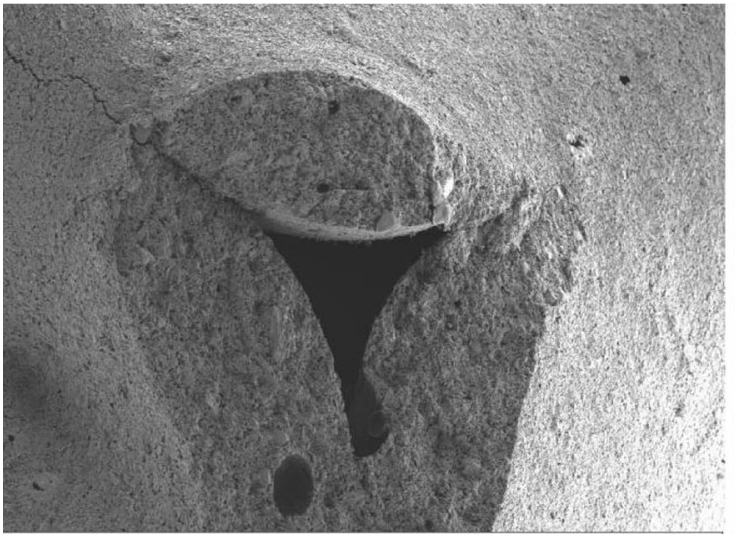

(a)

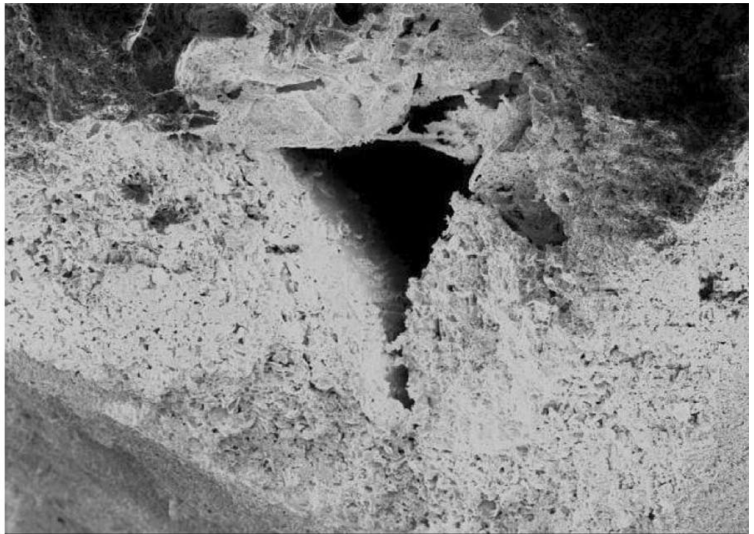

(b)

Fig. 4 SEM image of a uncoated and $\mathbf{b}$ coated strut and window of ceramic foam

\section{Effect of various parameters on methylation of toluene}

The significance of the use of coated ceramic foam in heterogeneous solid-catalytic reaction was studied by the effects of certain process parameters on a selective reaction, such as, contact time of catalyst slurry with ceramic foam blocks, catalyst loading, reactants mole ratio, temperature of the reaction, etc. 
Table 1 Quantitative chemical analysis of H-ZSM-5 and uncoated ceramic foam by energy dispersive X-ray spectroscopic analysis

\begin{tabular}{lll}
\hline Elements & H-ZSM-5 (wt\%) & Bare ceramic foam (wt\%) \\
\hline $\mathrm{Al}$ & 6.01 & 0 \\
$\mathrm{Si}$ & 93.99 & 99.87 \\
$\mathrm{Ti}$ & 0 & 0.13 \\
Total & 100 & 100 \\
\hline
\end{tabular}

Table 2 BET surface area of H-ZSM-5 coated and uncoated ceramic foam

\begin{tabular}{ll}
\hline Samples & Surface area $\left(\mathrm{m}^{2} / \mathrm{g}\right)$ \\
\hline H-ZSM-5 powder & 260 \\
Uncoated ceramic foam & 13.27 \\
Coated ceramic foam & 21.65 \\
\hline
\end{tabular}

\section{Effect of contact time of catalyst slurry}

with the ceramic foam block on catalyst loading

The effect of catalyst amount has been studied by varying the H-ZSM-5 quantity in slurry, keeping all other slurry properties constant. It is observed from Fig. 6, that the increase in H-ZSM-5 amount in slurry increases the percent catalyst loading up to $10 \%(\mathrm{~g} / \mathrm{mL})$ slurry concentration. Although catalyst loading increased above this concentration up to $20 \%$ (W/V), blocking of the pores of foam started due to the high concentration of slurry which is not acceptable. In addition, at $30 \%$ slurry concentration no change of catalyst loading on ceramic block could be seen, as all the pores were blocked and no space was left blank for further dip-coating. Henceforth, the percentage of coating remained constant beyond this point. Thus, with the perspective of satisfactory catalyst loading without blockage of pore could have been achieved with $10 \%(\mathrm{~g} /$ $\mathrm{mL}$ ) catalyst concentration in slurry.

\section{Comparison of catalytic activity between H-ZSM-5 pellet and foam-supported H-ZSM-5}

Commercial H-ZSM-5 was chosen as the catalyst for toluene methylation reaction. For this purpose, a comparison was made between the pellet H-ZSM-5 catalyst and catalyst coated on foam in terms of toluene conversion under identical reaction condition and constant amount of catalyst. Figure 7 shows about 32\% increase in initial conversion for foam-coated H-ZSM-5 in comparison to pellet catalyst. It was also observed that bare $\mathrm{SiC}$ foam has no catalytic activity towards the same reaction. This experiment proves the effectiveness of ceramic foamcoated catalyst over pelleted one, which enlightens the fact of better industrial application of the coated catalyst. In addition, the price of foam is also very low.

\section{Reaction conditions}

Reactor temperature $400{ }^{\circ} \mathrm{C}$, preheater temperature $350{ }^{\circ} \mathrm{C}$, chiller temperature $-15^{\circ} \mathrm{C}$, weight of catalyst $1 \mathrm{~g}, \mathrm{~N}_{2}$ flow rate $2 \times 10^{-4} \mathrm{~mol} / \mathrm{min}$, toluene flow rate $0.0025 \mathrm{~mol} / \mathrm{min}$, molar ratio (toluene:methanol) 1:2.

\section{Effect of feed rate on conversion}

To check the gas film diffusion effect on toluene methylation reaction, the feed rate of toluene has been varied up to $0.0045 \mathrm{~mol} / \mathrm{min}$, keeping all other reaction parameters constant. The conversion has been plotted against toluene flow rate in Fig. 8. It has been observed that initially the conversion increases linearly up to about $0.0025 \mathrm{~mol} / \mathrm{min}$ and after that it levels off. It may be inferred that within the flow rate $0.003 \mathrm{~mol} / \mathrm{min}$, the reactor behaves as a plug flow reactor as the conversion is changing with feed rate.
Fig. 5 a Nitrogen adsorption desorption isotherm and $\mathbf{b}$ pore volume distribution of H-ZSM5
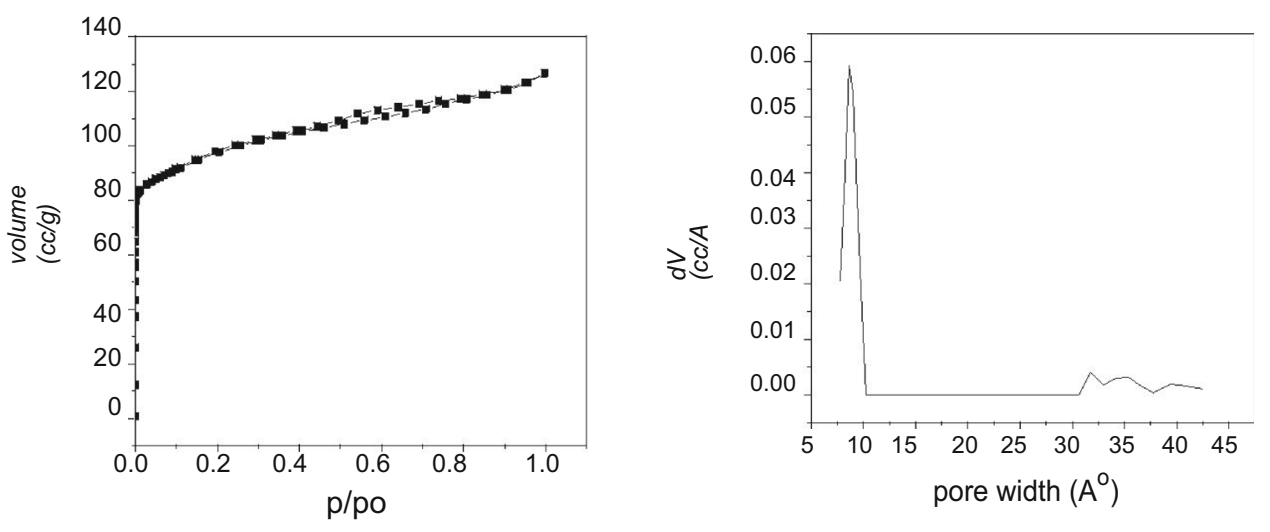


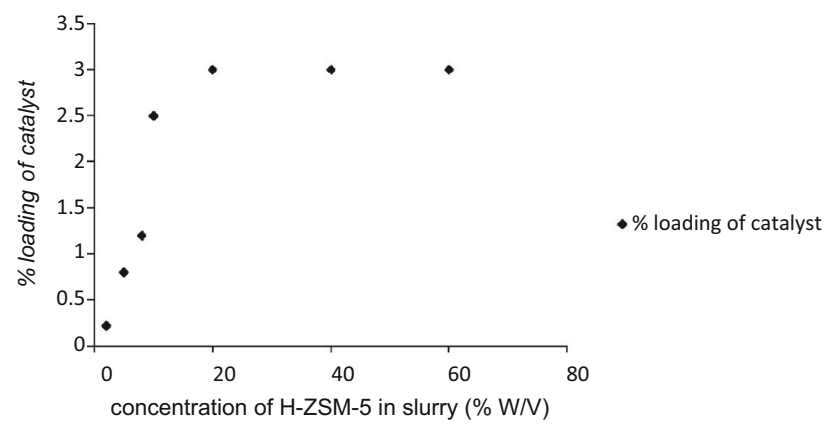

Fig. 6 Effect of catalyst concentration on catalyst loading

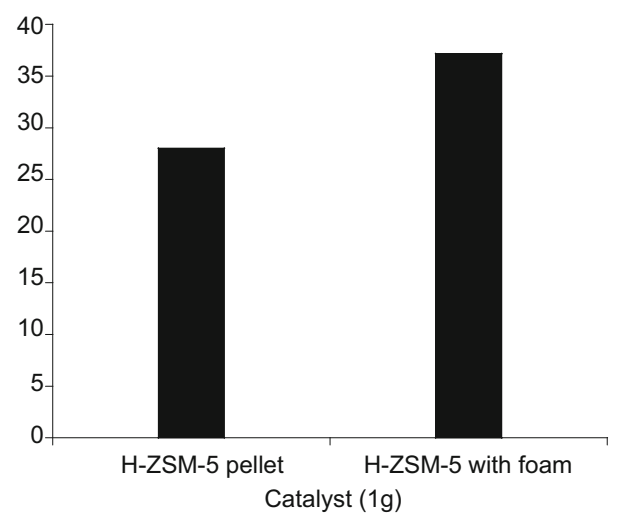

Fig. 7 Comparison for H-ZSM-5 pellet catalyst and H-ZSM-5 supported on foam

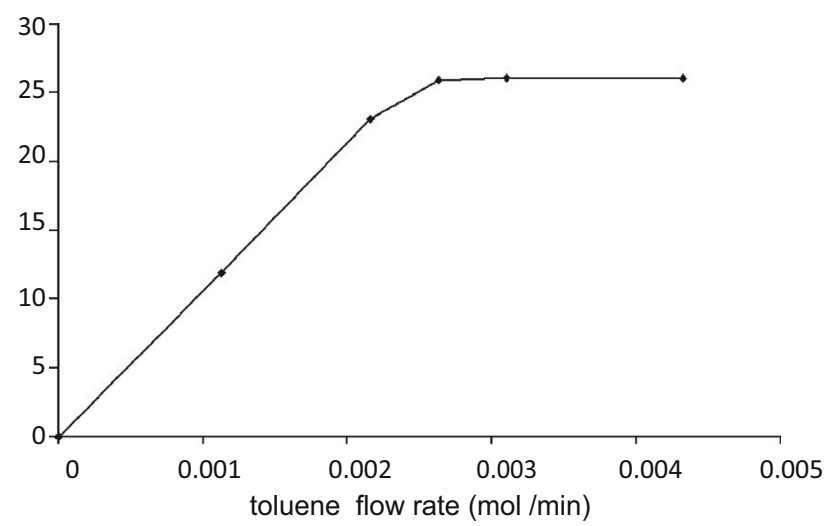

Fig. 8 Effect of feed rate on conversion

\section{Reaction conditions}

Reactor temperature $400{ }^{\circ} \mathrm{C}$, preheater temperature $350{ }^{\circ} \mathrm{C}$, chiller temperature $-15^{\circ} \mathrm{C}$, weight of catalyst in each block $0.64 \mathrm{~g}$, molar ratio (toluene:methanol) 1:2.

\section{Effect of temperature on conversion}

The search for an effective temperature region for obtaining maximum conversion is an essential part of the heterogeneous reaction study and in this purpose, the reaction was performed at $300,350,400,450$ and $470{ }^{\circ} \mathrm{C}$. It has been observed that, near $470{ }^{\circ} \mathrm{C}$, coke formation predominates and rapid deactivation starts, proved by the blackening of the catalyst surface and hence the catalyst activity declines. The conversions obtained at different temperatures at $10 \mathrm{~min}$ reaction time are plotted and shown in Fig. 9. It is found that by increasing temperature, conversion increases, but after $450{ }^{\circ} \mathrm{C}$ no further increase in conversion was observed, rather the conversion dropped down with further increase in temperature. So, for generating the kinetic data, the maximum temperature for the reaction was chosen to be $450{ }^{\circ} \mathrm{C}$. The kinetic study would be performed at varying temperatures from 350 to $450{ }^{\circ} \mathrm{C}$, because from $350{ }^{\circ} \mathrm{C}$ onwards a rapid increase in conversion was noted.

\section{Reaction conditions}

Chiller temperature $-15^{\circ} \mathrm{C}$, weight of catalyst $0.502 \mathrm{~g}$, $\mathrm{N}_{2}$ flow rate $2 \times 10^{-4} \mathrm{~mol} / \mathrm{min}$, toluene flow rate $0.0039 \mathrm{~mol} / \mathrm{min}$, molar ratio (toluene:methanol) $1: 2$.

\section{Effect of mole ratio on conversion}

The effect of reactant concentration on conversion has been studied varying mole ratio of toluene to methanol from 1:1 to $2: 1$, keeping moles of methanol constant. It is observed from Fig. 10 that with the increase of the mole ratio of toluene to methanol, the conversion increases. For carrying out the successive runs, the reactant mole ratio was chosen within this range.

\section{Reaction conditions}

Reactor temperature $400{ }^{\circ} \mathrm{C}$, preheater temperature $350{ }^{\circ} \mathrm{C}$, chiller temperature $-15^{\circ} \mathrm{C}$, weight of catalyst

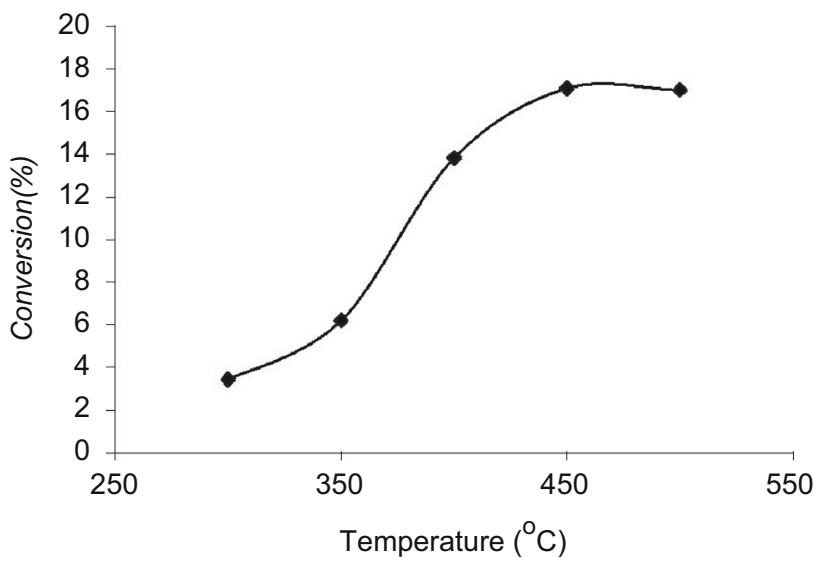

Fig. 9 Effect of temperature 


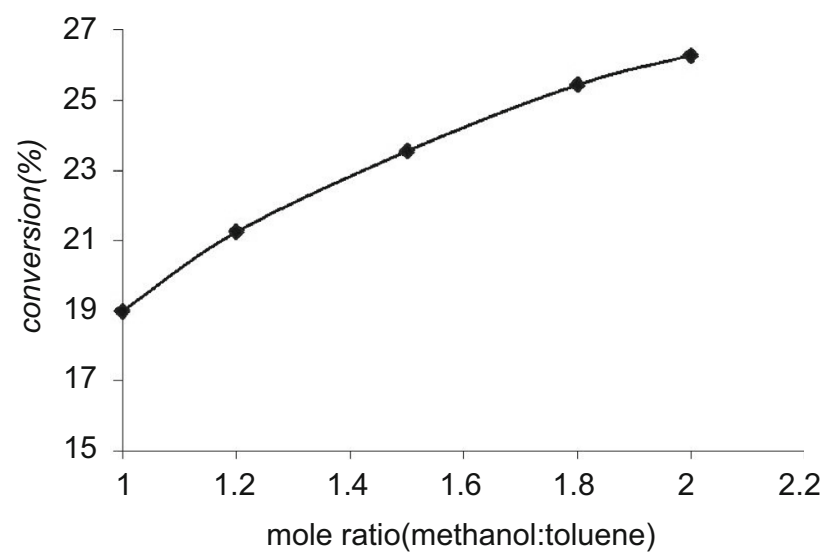

Fig. 10 Effect of mole ratio on conversion of toluene

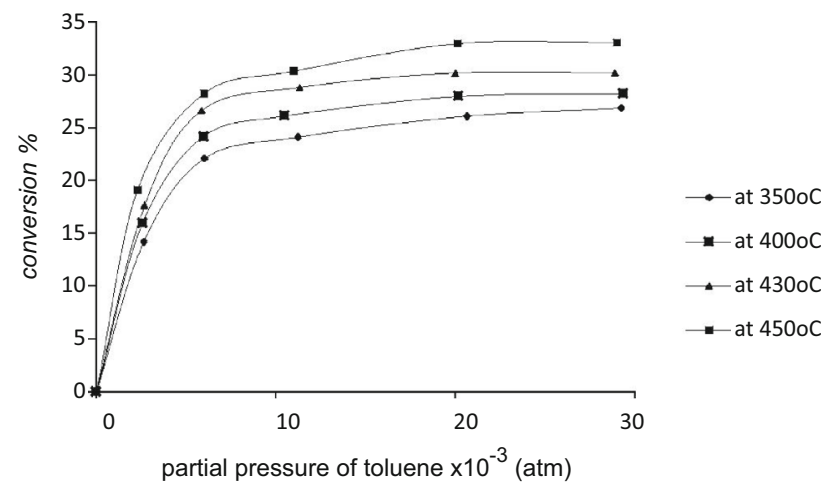

Fig. 11 Effect of partial pressure of toluene on conversion at different temperatures

$0.64 \mathrm{~g}, \mathrm{~N}_{2}$ flow rate $2 \times 10^{-4} \mathrm{~mol} / \mathrm{min}$, toluene flow rate $0.003 \mathrm{~mol} / \mathrm{min}$.

\section{Effect of partial pressure of toluene on conversion}

The effect of toluene partial pressure on conversion is shown in Fig. 11. The nature of the plot shows that up to about $5 \times 10^{-3} \mathrm{~atm}$ partial pressure, there is a rapid increase in conversion, after which, the rate of increase in conversion diminishes, following a parabolic path. This nature is an example of surface reaction controlled mechanism.

\section{Reaction conditions}

Chiller temperature $-15^{\circ} \mathrm{C}, \mathrm{N}_{2}$ flow rate $2 \times 10^{-4} \mathrm{~mol} /$ min, molar ratio (toluene:methanol) 1:2.

\section{Effect of number of foam blocks on conversion}

The effect of increase in catalyst weight was studied by varying the number of $\mathrm{SiC}$ foam blocks in the reactor.

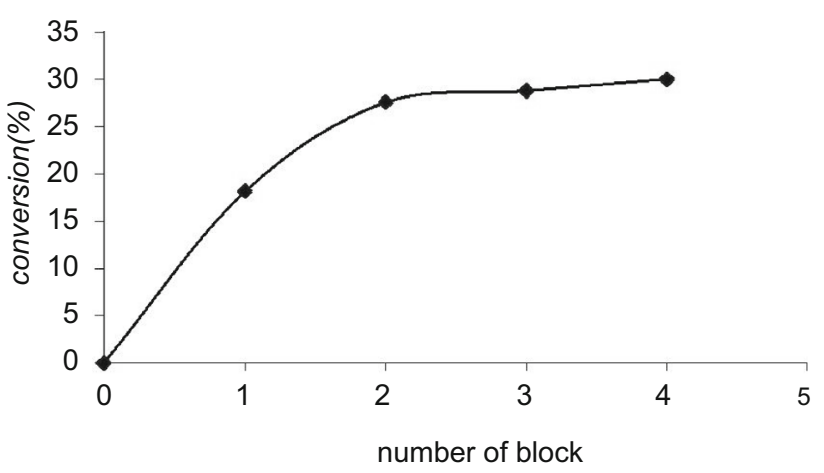

Fig. 12 Effect of number of blocks on conversion

Figure 12 shows that as the number of catalyst block increases, which in turn assumes the multiples of the amount of catalyst in a single block, the initial conversion increases up to two blocks of $\mathrm{SiC}$ foam, but with further increase in number, the conversion remains almost constant. The kinetic study has been performed taking a single block of catalyst.

\section{Reaction conditions}

Reactor temperature $400{ }^{\circ} \mathrm{C}$, preheater temperature $350{ }^{\circ} \mathrm{C}$, chiller temperature $-15^{\circ} \mathrm{C}$, weight of catalyst in each block $0.152 \mathrm{~g}, \quad \mathrm{~N}_{2}$ flow rate $2 \times 10^{-4} \mathrm{~mol} / \mathrm{min}$, toluene flow rate $0.0039 \mathrm{~mol} / \mathrm{min}$, molar ratio (toluene:methanol) 1:2.

\section{Effect of regeneration}

The used deactivated foam-supported catalyst was regenerated at $600{ }^{\circ} \mathrm{C}$ for $4 \mathrm{~h}$ in air flow to burn off the carbonaceous deposits on the catalyst. The conversions obtained in three successive regeneration cycles are shown in Fig. 13. The conversion obtained with fresh catalyst is

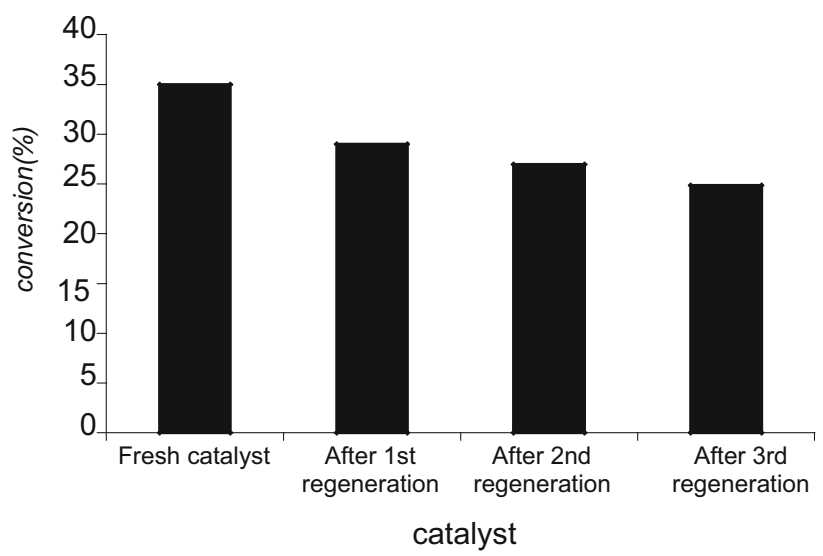

Fig. 13 Effect of regeneration of H-ZSM-5 coated $\mathrm{SiC}$ foam on conversion 
$35 \%$, whereas the conversion with catalyst after the third regeneration is $24.8 \%$. So, there is $29 \%$ reduction in conversion after three times regeneration.

\section{Reaction conditions}

Reactor temperature $400{ }^{\circ} \mathrm{C}$, preheater temperature $350{ }^{\circ} \mathrm{C}$, chiller temperature $-15^{\circ} \mathrm{C}$, weight of catalyst $1 \mathrm{~g}, \mathrm{~N}_{2}$ flow rate $2 \times 10^{-4} \mathrm{~mol} / \mathrm{min}$, toluene flow rate $0.0039 \mathrm{~mol} / \mathrm{min}$, molar ratio (toluene:methanol) 1:2.

\section{Effect of $W / F$ variation on conversion}

The effect of $W / F$ on conversion has been studied at five different temperatures $\left(350-450{ }^{\circ} \mathrm{C}\right)$ and will be utilized for kinetic analysis. Figure 14 shows that all the plots are having a sharp rise of conversion with $W / F$.

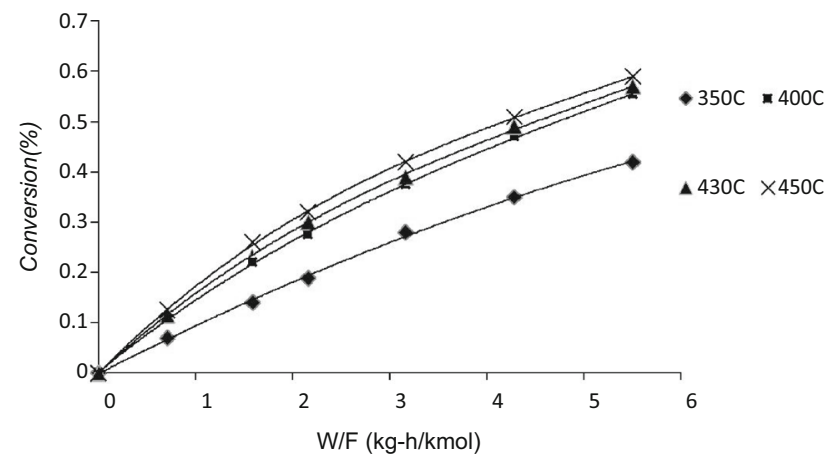

Fig. 14 Effect of $W / F$ variation on conversion

\section{Reaction conditions}

Chiller temperature $-15{ }^{\circ} \mathrm{C}, \mathrm{N}_{2}$ flow rate $2 \times 10^{-4} \mathrm{~mol} /$ min, toluene flow rate $0.0039 \mathrm{~mol} / \mathrm{min}$, molar ratio (toluene:methanol) 1:2.

\section{Langmuir-Hinshelwood kinetic model}

In case of heterogeneous catalysis, Langmuir-Hinshelwood approach may be considered for the derivation of rate equation. Alkylation of toluene with methanol to form xylene and water can be represented by the following equation:

$$
\begin{aligned}
\mathrm{C}_{6} \mathrm{H}_{5} \mathrm{CH}_{3}(\mathrm{~A})+\mathrm{CH}_{3} \mathrm{OH}(\mathrm{B}) \rightarrow & \mathrm{C}_{6} \mathrm{H}_{5}\left(\mathrm{CH}_{3}\right)_{2}(\mathrm{C}) \\
& +\mathrm{H}_{2} \mathrm{O}(\mathrm{D}) .
\end{aligned}
$$

Considering, D is not adsorbing on the catalyst surface compared to other hydrocarbons, the following cases have been considered.

\section{Model 1}

It is considered that ' $\mathrm{B}$ ' was not adsorbed on catalyst surface and the surface reaction is rate controlling.

$-r=\frac{K p_{\mathrm{A}} p_{\mathrm{B}}}{1+K_{\mathrm{A}} p_{\mathrm{A}}+K_{\mathrm{C}} p_{\mathrm{C}}} \quad K=k_{\mathrm{s}} K_{\mathrm{A}}$.

\section{Model 2}

This model is considered as dual site mechanism where surface reaction is irreversible and is the rate controlling step.

\begin{tabular}{|c|c|c|c|c|c|c|}
\hline & Temperature (K) & $k_{\mathrm{s}}$ & $K_{\mathrm{A}}$ & $K_{\mathrm{B}}$ & $K_{\mathrm{C}}$ & Resnorm \\
\hline \multirow[t]{4}{*}{ Model 1 (Eq. 1) } & 623 & 0.2782 & 4.08 & - & 0.6905 & 0.0008 \\
\hline & 673 & 0.5297 & 2.5140 & - & 0.3309 & 0.00062 \\
\hline & 703 & 0.7471 & 1.6250 & - & 0.1973 & 0.0016 \\
\hline & 723 & 0.9424 & 1.3505 & - & 0.0797 & 0.0005 \\
\hline \multirow[t]{4}{*}{ Model 2 (Eq. 2) } & 623 & 0.1738 & 4.9027 & -0.6684 & -1.7733 & 0.00085 \\
\hline & 673 & 0.9920 & -9.9385 & 1.5850 & 5.6456 & 0.00062 \\
\hline & 703 & 1.4229 & 1.7906 & 2.7341 & 4.4113 & 0.0013 \\
\hline & 723 & 1.3 & 2.36 & 5.3 & 2.5 & 0.0011 \\
\hline \multirow[t]{4}{*}{ Model 3 (Eq. 3) } & 623 & -2.8803 & -0.4743 & 3.6094 & 0.5600 & 0.00054 \\
\hline & 673 & 1.3702 & 3.2943 & 1.4999 & 2.9060 & 0.00035 \\
\hline & 703 & 1.5006 & 3.14 & 1.488 & 3.1927 & 0.0017 \\
\hline & 723 & 1.6927 & 3.0095 & 1.4522 & 3.39 & 0.0013 \\
\hline
\end{tabular}

Table 3 Kinetic and adsorption constants estimated by non-linear curve fitting analysis

Resnorm: $\operatorname{sum}\left(\left(\text { fun }\left(x, x_{\text {data }}\right)-\text { data }\right)^{2}\right)$ 


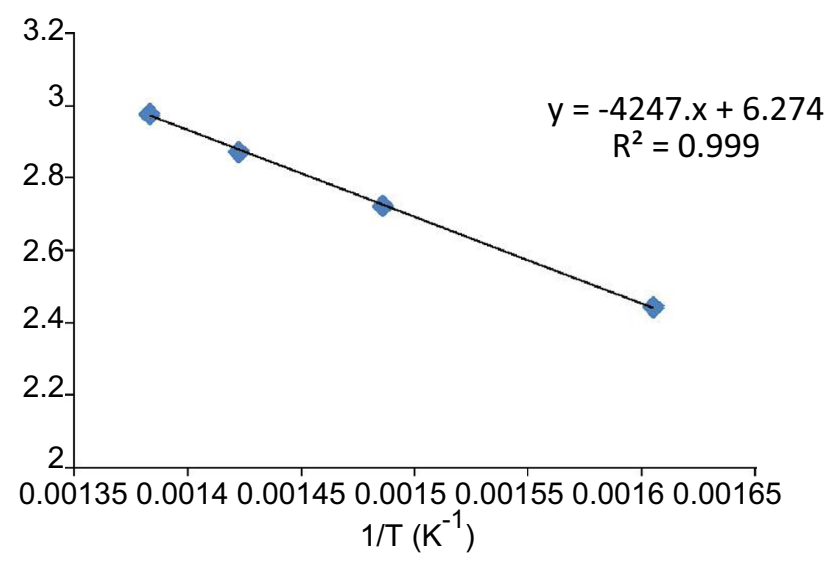

Fig. 15 Arrhenius plot

$-r=\frac{K p_{\mathrm{A}} p_{\mathrm{B}}}{\left(1+K_{\mathrm{A}} p_{\mathrm{A}}+K_{\mathrm{B}} p_{\mathrm{B}}+K_{\mathrm{C}} p_{\mathrm{C}}\right)^{2}} \quad K=k_{\mathrm{s}} K_{\mathrm{A}} K_{\mathrm{B}}$.

Model 3

This model described the dual site mechanism with adsorption of 'A' as the slowest step.

$-r=\frac{K_{\mathrm{A}} p_{\mathrm{A}}}{1+K^{\prime} p_{\mathrm{C}}^{2} / p_{\mathrm{B}}+K_{\mathrm{B}} p_{\mathrm{B}}+K_{\mathrm{C}} p_{\mathrm{C}}} \quad K^{\prime}=K_{\mathrm{C}} K_{\mathrm{D}} / K_{\mathrm{B}} k_{\mathrm{s}}$,

where $k_{\mathrm{s}}$ is the kinetic rate constant, $K$ is the equilibrium constant and $K_{\mathrm{A}}, K_{\mathrm{B}}, K_{\mathrm{C}}, K_{\mathrm{D}}$ are the equilibrium adsorption constant for species A, B, C, D, respectively.

\section{Estimation of parameters}

Kinetic runs were carried above the minimum feed flow rate up to which mass transfer effect is considerable. The minimum feed flow rate was determined at $0.0039 \mathrm{~mol} / \mathrm{min}$ (Fig. 8). Alkylation reaction of toluene with methanol was carried out at four different temperatures 323, 673, 703 and $723 \mathrm{~K}$. W/F was varied and the variation in conversion is graphically shown in Fig. 14.

For each temperature, rates of reaction were obtained by differential analysis of the plug flow reactor equation

$r_{\mathrm{obs}}=\frac{\mathrm{d} X}{\mathrm{~d}(W / F)}$.

The values of $r_{\mathrm{obs}}$, which are expressed in Eq. 4, can be calculated from the slope of Fig. 13.

The non-linear method of analysis using Matlab 7.9.0 was used for the model analysis and estimation of rate parameters. The results of the non-linear analysis are shown in Table 3.

It can be observed from Table 3 that the parameters show negative values for Model 2 and Model 3. Therefore, these two models were rejected. In Model 1, kinetic constants increase and equilibrium adsorption constants decrease with increasing temperature following the usual behavior.

The kinetic constant evaluated was used to determine the activation energy and frequency factor using Arrhenius relationship, $k=A_{\mathrm{o}} \exp \left(-E_{\mathrm{a}} / R T\right)$. A plot of $\ln k$ versus $1 / T$ exhibited a straight line as shown in Fig. 14. The apparent activation energy was calculated to be $40 \mathrm{~kJ} / \mathrm{mol}$ and frequency factor $5.3 \times 10^{2} \mathrm{kmol} / \mathrm{kg} \mathrm{h}$ (Fig. 15).

\section{Conclusion}

Washcoating process with H-ZSM-5 increased the surface area of blank foam from 13.87 to $21.66 \mathrm{~m}^{2} / \mathrm{g}$. The reusability of catalyst over ceramic foam support was proved. The activity was retained even after third time regeneration. Langmuir-Hinshelwood kinetic approach was proposed. The activation energy and frequency factor was calculated and found to be $40 \mathrm{~kJ} / \mathrm{mol}$ and $5.3 \times 10 \mathrm{kmol} / \mathrm{kg} \mathrm{h}$. Optimum catalyst concentration in slurry for washcoating was found to be $10 \%$ (W/V) catalyst powder in slurry.

Acknowledgements Debarpita Ghosal was supported by IIT Kharagpur.

Open Access This article is distributed under the terms of the Creative Commons Attribution 4.0 International License (http:// creativecommons.org/licenses/by/4.0/), which permits unrestricted use, distribution, and reproduction in any medium, provided you give appropriate credit to the original author(s) and the source, provide a link to the Creative Commons license, and indicate if changes were made.

\section{References}

1. Meille V (2006) Review on methods to deposit catalysts on structured surfaces. Appl Catal A 315:1-17

2. Twigg MV, Richardson JT (2002) Theory and application of ceramic foam catalysts. Trans IChemE 80(Part A):183-189

3. Twigg MV, Richardson JT (2007) Fundamentals and applications of structured ceramic foam catalysts. Ind Eng Chem Res 46:4166-4177

4. Palomares EG, Eder-Mirth E, Lercher JA (1997) Selective alkylation of toluene over basic zeolites: an in situ infrared spectroscopic investigation. J Catal 168:442-449

5. Dumitriu E, Hulea V, Kaliaguine S, Huang MM (1996) Transalkylation of alkyl aromatic hydrocarbons in the presence of ultrastable Y zeolites transalkylation of toluene with trimethyl benzenes. Appl Catal A 135:57-81

6. Ratnasamy PR, Bhat N, Pokhriyal SK, Hegde SG, Kumar R (1989) Reactions of aromatic hydrocarbons over zeolite $\beta$. J Catal 119:65-70 
7. Das J, Bhat YS, Halgeri AB (1994) Transalkylation and disproportionation of toluene and $\mathrm{C}_{9}$ aromatics over zeolite beta. Catal Lett 23:161-168

8. Yashima T, Ahmad H, Yamazaki K, Katsuta M, Hara N (1970) Alkylation on synthetic zeolites I. Alkylation of toluene with methanol. J Catal 16:273-280

9. Yashima T, Sato K, Hayasaka T, Hara N (1972) Alkylation on synthetic zeolites III. Alkylation of toluene with methanol and formaldehyde on alkali cation exchanged zeolites. J Catal 26:303-312

10. Mantha R, Bhatia S, Rao MS (1991) Kinetics of deactivation of methylation of toluene over H-ZSM-5 and hydrogen mordenite catalysts. Ind Eng Chem Res 30:281-286

11. Chen NY, Kaeding WW, Dwyer FG (1979) Para-directed aromatic reactions over shape-selective molecular sieve zeolite catalysts. J Am Chem Soc 101(22):123-130

12. Kaeding WW, Chu C, Young LB, Weinstein B, Buttery SA (1981) Selective alkylation of toluene with methanol to produce para-xylene. J Catal 67:159-174

13. Uguina MA, Sotelo JL, Serrano DP (1991) Toluene disproportionation over ZSM-5 zeolite effects of crystal size, silicon-toaluminum ratio, activation method and pelletization. Appl Catal 76:183-198

14. Wu P, Komatsu T, Yashima T (1998) Selective formation of $p$ xylene with disproportionation of toluene over MCM-22 catalysts. Microporous Mesoporous Mater 22:343-356

15. Mirth G, Cejka J, Lercher JA (1993) Transport and isomerisation of xylenes over HZSM-5 zeolites. J Catal 139:24-33

16. Eder-Mirth G, Lercher JA (1994) On the role of product isomerization for the shape selective toluene methylation over H-ZSM-5. J Catal 147:199-206

17. Cejka J, Zilkova N, Wichterlova B, Eder-Mirth G, Lercher JA (1996) Decisive role of transport rate of products for zeolite pamselectivity: effect of coke deposition and external surface silylation on activity and selectivity of HZSM-5 in alkylation of toluene. Zeolites 17:265-271

18. Seijiger GBF, Oudshoorn OL, van Kooten WEJ, Jansen JC, van Bekkum H, van den Bleek CM, Calis HPA (2000) In situ synthesis of binderless ZSM-5 zeolitic coatings on ceramic foam supports. Microporous Mesoporous Mater 39:195-204

19. Buciuman FC, Czarnetzki BK (2001) Preparation and characterization of ceramic foam supported nanocrystalline zeolite catalysts. Catal Today 69:337-342

20. Xu X, Moulijn JA (1998) Preparation of monolithic catalysts by dip coating. Stud Surf Sci Catal 118:845-854

21. Rollmann LD, Walsh DE (1979) Shape selectivity and carbon formation in zeolites. J Catal 56:139-140

22. Miradatos C, Barthomeuf D (1981) Superacid sites in zeolites. J Chem Soc Chem Commun 39-40

23. Vu DV, Miyamoto M, Nishiyama N, Egashira Y, Ueyama K (2006) Selective formation of $p$-xylene over H-ZSM-5 coated with polycrystalline silicalite crystals. J Catal 243:389-394

24. Zamaro J, Ulla MA, Miro ED (2005) Zeolite washcoating onto cordierite honeycomb reactors for environmental applications. Chem Eng J 106:25-33
25. Lee CS, Park TJ, Lee WY (1993) Alkylation of toluene over double structure ZSM-5 type catalysts covered with a silicalite shell. Appl Catal A 96:151-161

26. Sad ME, Padró CL, Apesteguia CR (2008) Synthesis of cresols by alkylation of phenol with methanol on solid acids. Catal Today 133:720-728

27. Datka J, Piwowarska Z, Rakoczy J, Sulikowski B (1986) Catalytic and acid properties of pentasil zeolites: isomerisation of $o$ xylene and alkylation of toluene. Zeolites 8:199-204

28. Beschmann K, Riekert L (1993) Isomerisation of xylene and methylation of toluene on zeolite H-ZSM-5. Compound kinetics and selectivity. J Catal 141:548-565

29. Young LB, Butter SA, Kaeding WW (1982) Shape selective reactions with zeolite catalysts III. Selectivity in xylene isomerization, toluene-methanol alkylation, and toluene disproportionation over ZSM-5 zeolite catalysts. J Catal 76:418-432

30. Jahn SL, Cardoso D (1989) Influence of the Si/Al ratio and ZSM5 crystallite size on the methylation of toluene. Catal Today 5:515-521

31. Ghiaci M, Abbaspur A, Arshadi M, Aghabarari B (2007) Internal versus external surface active sites in ZSM-5 zeolite, Part 2: Toluene alkylation with methanol and 2-propanol catalyzed by modified and unmodified $\mathrm{H}_{3} \mathrm{PO}_{4} / \mathrm{ZSM}-5$. Appl Catal A 316:32-46

32. Cavallaro S, Pino L, Tsiakaras P, Giordano N, Rao BS (1987) Alkylation of toluene with methanol III para-selectivity on modified ZSM-5 zeolites. Zeolites 7:409-411

33. Vayssilov G, Yankov M, Hamid A (1993) Para-selective alkylation of toluene with methanol over ZSM-5 zeolites A kinetic model. Appl Catal A 94:117-130

34. Lee B-J, Ikal W (1985) Kinetic analysis of ethylation of toluene on HZSM-5. Ind Eng Chem Prod Res Dev 24(2):201-205

35. Lonyi F, Engelhardt J, Kallo D (1991) Para-selectivity of toluene ethylation over ZSM-5 catalysts. Zeolites 11:169-177

36. Parikh PA, Subrahmanyam N, Bhat YS, Halgeri AB (1994) Kinetics of zeolite-catalysed toluene isopropylation. Chem Eng J 54:79-86

37. Yoo J-W, Lee CW, Park SE, Ko J (1999) Alkylation of catechol with $t$-butyl alcohol over acidic zeolites. Appl Catal A 187:225-232

38. Richardson JT, Garrait M, Hung J-K (2003) Carbon dioxide reforming with $\mathrm{Rh}$ and $\mathrm{Pt}-\mathrm{Re}$ catalysts dispersed on ceramic foam supports. Appl Catal A 255:69-82

39. Aleksandrov YuA, Tsyganova EI, Ivanovskaya KE, Vorozheiki IA (2002) Kinetic regularities of the heterogeneous catalytic oxidation of carbon monoxide on ceramic foam supported catalysts. Russ J Gen Chem 72(1):13-16 (translated from Z Obshchei Khimii 72(1):17-20)

40. Ledoux MJ, Pham-Huu C, Chinaelli RR (1996) Catalysis with carbides. Curr Opin Solid State Mater Sci 1(1):96-100

41. Sweeting TB, Norris DA, Strom LA, Morris JR (1995) Reticulated ceramics for catalyst support applications. ChemInform 26:50 